\title{
Technical Trading Rules in Emerging Stock Markets
}

\author{
Stefaan Pauwels, Koen Inghelbrecht, Dries Heyman, and Pieter Marius
}

\begin{abstract}
Literature reveals that many investors rely on technical trading rules when making investment decisions. If stock markets are efficient, one cannot achieve superior results by using these trading rules. However, if market inefficiencies are present, profitable opportunities may arise. The aim of this study is to investigate the effectiveness of technical trading rules in 34 emerging stock markets. The performance of the rules is evaluated by utilizing White's Reality Check and the Superior Predictive Ability test of Hansen, along with an adjustment for transaction costs. These tests are able to evaluate whether the best model performs better than a buy-and-hold benchmark. Further, they provide an answer to data snooping problems, which is essential to obtain unbiased outcomes. Based on our results we conclude that technical trading rules are not able to outperform a naïve buy-and-hold benchmark on a consistent basis. However, we do find significant trading rule profits in 4 of the 34 investigated markets. We also present evidence that technical analysis is more profitable in crisis situations. Nevertheless, this result is relatively weak.
\end{abstract}

Keywords - technical trading rules, Reality Check, Superior Predictive Ability, emerging stock markets, data snooping

\section{INTRODUCTION}

$\mathrm{O}$ $\mathrm{NE}$ of the most discussed topics in financial literature is the efficiency of speculative markets. If financial markets are fully efficient, future prices can't be predicted based on past price movements, which eliminates the usefulness of technical trading rules. However Lo [1] introduces the Adaptive Market Hypothesis, in which the relationship between risk and return is claimed not to be stable over time. Hence, the efficiency of markets is considered to be a dynamic process. This means that profitable technical trading opportunities may occur from time to time. In addition, recent literature (e.g., McKenzie [2], Marshall, Cahan and Cahan [3]) shows that inefficiencies may occur in emerging stock markets, which is in favor of technical analysis. We use these insights to investigate whether 34 worldwide emerging stock markets provide a basis for technical trading rules.

In this research, we contribute to the literature in several ways. Firstly, a total of 11,350 technical trading algorithms are drawn from 13 strategies, which is one of the largest number of models ever used in a survey of this kind. Furthermore, this sample is tested on 34 emerging stock market indices, while

Stefaan Pauwels. Department of Financial Economics, Ghent Univeristy, Ghent University, Woodrow Wilsonplein 5D (phone: +32498676446; e-mail stefaan.pauwels@ugent.be).

Koen Inghelbrecht, Department of Financial Economics, Ghent Univeristy, Ghent University, Woodrow Wilsonplein 5D (e-mail: koen.inghelbrecht@ugent.be).

Dries Heyman, Department of Financial Economics, Ghent Univeristy, Ghent University, Woodrow Wilsonplein 5D (e-mail: dries.heyman@ugent.be).

Pieter Marius, Financial Data Management, Dexia (e-mail: npieter.marius@dexia.com) previous research tends to focus on one or a few markets. Thirdly, we compare the results of the best trading rule to the full universe of rules. We use a new test for superior predictive ability (SPA). The new test improves favorably to the reality check for data snooping $(\mathrm{RC})$, because it is more powerful and less sensitive to poor and irrelevant rules. The Superior Predictive Ability test is a test that can be used for comparing the performances of several technical trading rules. The forecasts are evaluated using a loss function, and the best rule is the one that produces the smallest expected loss. This approach is introduced by White [4] and supported by Sullivan, Timmermann and White [5], Hansen [6], and Hsu, Hsu and Kuan [7]. According to their work, one is able to eliminate data snooping problems by using this method, which is essential to achieve unbiased results. Finally, this survey provides an adjustment for transaction costs. As far as we know, a research of this extent hasn't been executed yet on emerging stock markets.

We find that technical analysis is significantly profitable in only 4 of the 34 countries after accounting for data snooping bias and transaction costs. Strong evidence is found for the fact that data snooping has an immense effect on technical trading rule performance evaluation. Further, evidence is presented that trading algorithms performed better during the recent economic crisis, which proves that market inefficiencies emerge from time to time. It is important to notice that this study only examines historical outperformance of technical trading rules. It still remains an open question how to detect the best trading rule ex ante.

The remainder of this paper is structured as follows: Section II gives a review on the existing literature related to our survey, section III describes the data, section IV sets out the methodology, section $\mathrm{V}$ discusses the results, and section VI concludes.

\section{LITERATURE REVIEW}

Technical trading rules are one of the oldest and most used techniques to forecast price movements in various financial markets. These methods are applied by economists to analyze the evolution of stock prices, and to detect buy and sell signals. For that reason, this subject has been widely studied by academics. Nevertheless, literature indicates that researchers are not able to present an unambiguous conclusion on technical analysis.

According to the efficient market hypothesis of Fama [8], security prices fully reflect all publicly available information. This implies that stock prices change randomly, and that it is impossible to forecast future security prices when studying information gained from past prices. Consequently, technical analysis does not add value. Proponents of this theory are Jensen [9], Malkiel [10]-[11], Li and Wang [12] and Chen, 
Huang and Lai [13]. On the other hand, academics as Lukac, Brorsen, Irwin [14], Brock, Lakonishok, and LeBaron [15], Sullivan, Timmermann and White [5], Gunasekarage and Power [16], Fifield, Power and Sinclair [17], Marshall, Cahan and Cahan [3] and Hsu, Hsu and Kuan [7] find positive evidence regarding the profitability of technical trading rules. We must emphasize that there still is no conclusive evidence on this subject. The field of technical trading rules is too complex and too evolving to draw definitive conclusions.

\section{A. Evidence from developed stock markets}

Over the years, numerous financial economists have found predictable patterns in stock prices, which mean that technical analysis may generate excess returns.

Important evidence in support of technical analysis in stock markets is provided by Brock, Lakonishok and LeBaron [15] (BLL, hereafter). In their survey they do not take transaction costs into account. Further, they are aware that data snooping may occur, superior trading rule performance is often a consequence of survivorship bias. When examining popular trading rules, BLL acknowledge that their superior results may be the consequence of luck. Bessembinder and Chen [18] argue that technical trading requires regular transactions. Therefore, they extend the survey of BLL by making a correction for transaction costs. While doing that, Bessembinder and Chen [18] find that the positive evidence of BLL disappears. Still, data snooping bias is not taken into account.

As an answer on these surveys, White [4] introduces the bootstrap Reality Check. He states that to mitigate data snooping problems, survivorship bias has to be countered. The only way to handle this problem is to compose a full universe of trading rules, instead of only investigating successful rules. The Reality Check tests the performance of the best technical trading rule in the context of the full universe of rules. By employing a performance statistic to the full set of models, this statistical procedure counters data snooping bias. Sullivan, Timmermann, and White [5] (STW, hereafter) utilize the Reality Check to evaluate technical trading profitability in the U.S. stock market, and find supportive evidence for the results of BLL in the period 1897-1986. Nevertheless, they find no proof of excess returns in the period 1987-1996, which was not in the sample of BLL. This evolution in empirical results may have various causes. First of all, the structure of stock markets may have changed over the years. Secondly, there is a possibility is that technical trading rules lose their predictive power when they are made public. This effect is investigated by Timmermann and Granger [19]. They notice that when the trading algorithms are published, the information they deliver is incorporated in stock prices. Therefore it will be impossible to consistently use the rules to beat the market. Thus, Timmermann and Granger conclude that the early users of technical trading rules may be able to achieve profitable results, but after publication, superior performance will not persist. Technical analysis is, in other words, self-destructive. This viewpoint is in support of Lo's Adaptive Market Hypothesis, which stated that market efficiency has to be seen as an evolutionary process. Although White presents a model that is able to make a correction for data snooping, Hansen [6] discovers some shortfalls. He states that the p-values the RC test delivers are inconsistent. Hansen claims that the Reality Check is sensitive to the inclusion of poor and irrelevant models, and consequently can be manipulated. Therefore, he introduces a new test for Superior Predictive Ability, which corrects the errors made by White. Hansen improves the Reality Check by using a studentized test statistic and a datadependent null distribution. Because of these changes, this procedure will be less sensitive when poor performing trading are included in the sample. Empirical work of Hansen and Lunde [20], Hsu, Hsu and Kuan [7] shows that Hansen's test for Superior Predictive Ability is more powerful than White's Reality Check.

In recent work of Marshall, Qian and Young [21], the conclusion is made that technical traders are not able to consistently beat the benchmark in the U.S. stock market from 1990 until 2004. However, evidence is presented that technical analysis is more applicable on small and illiquid stocks, which are likely to be present in emerging stock markets.

\section{B. Evidence from emerging stock markets}

The overall conclusion is that in most cases technical analysis is not profitable in financial markets of highly developed countries, which supports at least the weak form of the efficient market hypothesis. Further, literature provides evidence that the predictive power of technical trading algorithms has decreased over the years. Nevertheless, researches raise questions about the efficiency of emerging markets. Lo and McKinlay [22], Fama and French [23], and McKenzie [2] indicate that inefficiencies may be present in these markets, which provides opportunities for technical analysis. As mentioned before, Marshall, Qian and Young [21] conclude that technical trading rules are more applicable on small, illiquid stocks. Furthermore, proponents of the Adaptive Market Hypothesis also indicate that younger stock markets provide more arbitrage opportunities compared to developed markets. In recent literature, a lot of economists use these insights to test technical trading benefits in emerging stock markets.

Gunasekarage and Power [16] uncover evidence that technical analysis indeed provides arbitrage opportunities in emerging markets. They investigate moving average rules in the stock markets of Bangladesh, India, Pakistan and Sri Lanka. Gunasekarage and Power find that in all of the countries except for India, the rules significantly outperform a naïve buy-and-hold portfolio. These results support the findings of Lo and McKinlay [22], Fama and French [23], and McKenzie [2], since India is the largest and most efficient market included in the sample of this survey.

Fifield, Power and Sinclair [17] then, examine whether or not two widely used technical trading rules - filter rules and moving averages - have been profitable in 11 European stock markets in the period 1991-2000. They find evidence of filter rule profits in 4 emerging markets - Greece, Hungary, Turkey and Portugal -, but when results of developed markets are 
considered, there is no evidence of superior performance. These results seem to indicate that the diversity in development of stock markets is more determinative for technical analysis profitability than geographical location.

A survey of $\mathrm{Li}$ and Wang [12] investigates technical analysis on the Chinese stock market, which is the largest emerging market in terms of market capitalization. they make a distinction between A-shares, which are reserved for domestic investors and B-shares, which are reserved for foreign investors. After transaction costs are included, they find no evidence of superior technical trading rules when considering A-shares. However, Li and Wang find excess returns when investigating B-shares. Since February 19, 2001, domestic investors are also permitted to trade B-shares. Li and Wang conclude that after this change in legislation, excess technical trading profits disappear.

Support for the efficient market hypothesis is provided by Chen, Huang and Lai [13], who find that positive technical trading results in eight Asian equity markets disappear when transaction costs and data snooping are taken into account. Another survey that investigates moving average rules in emerging stock markets is provided by Papathanasiou and Samitas [24]. They use the methodology of Brock, Lakonishok and LeBaron [15] and apply it on the Cyprus Stock Exchange, which is a small and non derivative market. Papathanasiou and Samitas state that when transaction costs are ignored, the trading rules significantly outperform a buyand-hold strategy over the 1998-2005 period. McKenzie [2] investigates technical trading profitability in 17 emerging stock markets relative to a U.S. benchmark. He states that some of the trading algorithms are able to achieve excess returns, and that the persistence of these results is more likely to appear in emerging markets.

We have to note that the above-mentioned studies on emerging markets do not acknowledge data snooping bias. Hsu, Hsu and Kuan [7] take this problem into account. They investigate technical trading profitability in Asian emerging stock markets (MSCI Emerging Markets Index, MSCI Brazil Index, MSCI South Korea Index, MSCI Malaysia Index, MSCI Mexico Index, and MSCI Taiwan Index), and use a stepwise test for Superior Predictive Ability. Hsu, Hsu and Kuan find that technical trading rules perform better in young stock markets than in developed markets. More, they provide further evidence in favour of Lo's [1] Adaptive Market Hypothesis, by stating that the profitability of technical analysis weakens over the years.

Other research that provides an answer on data snooping bias is conducted by Marshall, Chan and Chan [3]. They give a straightforward view on how White's Reality Check can be used to examine technical trading rule profitability. They test more than 5,000 trading rules on the 23 developed markets and the 26 emerging markets of the Morgan Stanley Capital Index, and report that the best performance is achieved in emerging stock markets. Nevertheless, Marshall, Chan and Chan conclude that the significance of the results is not strong enough exclude the possibility that the results are obtained due to luck.

\section{DATA}

\section{A. Stock market indices}

Unlike many previous studies that focus on one or a few markets, we test profitability of technical trading rules on a larger sample of indices. We apply each model on the end-ofday returns of 34 worldwide emerging stock markets. The reason why we focus on these specific countries is because of the fact that recent literature of Fifield, Power and Sinclair [17] and Marshall, Chan and Chan [3] has shown that superior outcomes are more likely to appear in emerging stock markets. We test whether these positive results will emerge when transaction costs and data snooping bias are taken into account. For each stock index, we use the longest possible time window. Further, we also examine a sub-period that represents the recent economic crisis, since market inefficiencies are likely to be present in this period. The summary statistics are presented in table I.

\section{B. Technical trading rules}

In order to achieve satisfactory results, it is very important to select a well composed sample of technical trading rules. In this paper, we have selected 13 trading systems, based on previous research of Lukac, Brorsen, Irwin [14], Sullivan, Timmermann and White [5], Hsu and Kuan [25] and Park and Irwin [26]. Each trading rule can be assigned to different categories: moving averages filter rules, channel breakouts, and momentum oscillator rules. A total 11,350 technical trading rules are drawn from these trading strategies.

\section{1) Moving Averages}

The most popular technical trading systems are moving averages. These models can be obtained by calculating the average of a fixed sample size of stock prices. For each day, a new average will be calculated. The plot line that is constructed by taking all the averages into account is called a moving average. The goal of moving average systems is to rule out the possibility that false trading systems will be generated by short-term price changes. Instead, long-term price trends can be detected. In this survey we use 5 moving average systems: Simple Moving Average with a band (MAB), Dual Moving Average Crossover (DMC), Moving Average Crossover (MAC), Exponential Moving Average Crossover (EMC) and Moving Average ConvergenceDivergence (MACD).

\section{2) Filter Rules}

Like moving averages, filter rules try to avoid false trading systems that are based on short-term price changes. Therefore these strategies filter out small price movements, and only generate trading signals in the case of larger price changes. In this paper, the Alexander's Filter Rule (ALX) is used.

\section{3) Price Channels}

The third category of technical trading systems that we use in our survey is the price channel. Sometimes this strategy is called support and resistance or trading range breakout. Trading signals are generated when a current price level 
passes the highest high or lowest low in a predefined time interval. We utilize 2 price channel systems: Outside Price Channel (CHL) and Bollinger Bands (BBA).

\section{4) Momentum Oscillator Rules}

Momentum rules utilize the magnitude of price changes to detect trading signals. They generate long (short) signals when a momentum indicator is greater (less) than a predefined threshold value. In this survey, the 5 following momentum oscillator rules are used: Relative Strength Index (RSI), Directional Indicator (DRI), Reference Deviation (REF), Williams \%R (WR) and Stochastic Oscillator (STO).

\section{Transaction costs}

To obtain reliable results, we impose transaction costs on each trade. The figures are based on literature of Munck [27] and Elkins/McSherry consultancy (2008). Unlike many previous studies that base their estimations process on dated research, our survey gives a realistic view on the actual situation.

\section{Methodology}

In order to examine the profitability of technical trading rules relative to a given benchmark, we need a statistical procedure that provides a test across the entire set of algorithms. Such a model is presented by White [4]. Building on previous research of Diebold and Mariano [28] and West [29], he introduces a Bootstrap Reality Check (RC). By testing the null hypothesis that the benchmark outperforms the entire set of technical trading rules, Sullivan, Timmermann and White [5] provide evidence that the RC-test is able to rule out data snooping bias.

Firstly, the Reality Check derives the performance of the trading rules relative to the benchmark by interpreting the mean return. If the predicted return of a trading rule $t$ is $\hat{Y}_{t}$, and the realized return is $Y_{t}$, we can define its loss as $L\left(Y_{t}\right.$, $\hat{Y}_{t}$ ). The best rule will be the one with the smallest loss. The relative performance of trading rule $\mathrm{k}$ at time $\mathrm{t}$, compared to the benchmark model, can be formulated as following:

$$
\mathrm{f}_{\mathrm{k}}(\mathrm{t}) \equiv \mathrm{L}\left(\mathrm{Y}_{\mathrm{t}}, \hat{\mathrm{Y}}_{\mathrm{o}, \mathrm{t}}\right)-\mathrm{L}\left(\mathrm{Y}_{\mathrm{t}}, \hat{\mathrm{Y}}_{\mathrm{k}, \mathrm{t}}\right), \quad \mathrm{k}=1, \ldots, \mathrm{m}, \quad \mathrm{t}=1, \ldots, \mathrm{n} .
$$

In order to find out whether the models $\mathrm{k}=1, \ldots, \mathrm{m}$ are able to produce excess returns, we test the hypothesis that the benchmark is not inferior to any of the trading rules. Let $u_{k}$ be the expected return of model $\mathrm{k}$ towards the benchmark. The hypothesis can be presented as following:

$$
\mathrm{u}_{\mathrm{k}}=\mathrm{E}\left[\mathrm{f}_{\mathrm{k}}(\mathrm{t})\right] \leq 0, \mathrm{k}=1, \ldots, \mathrm{m} .
$$

In case that for each technical trading rule $\mathrm{k}(\mathrm{k}=1, \ldots, \mathrm{m}), \mathrm{u}_{\mathrm{k}}$ $\equiv \mathrm{E}\left(\mathrm{f}_{\mathrm{k}}\right)$ is well-defined, we can formulate an m-dimensional vector $u$ by

$$
u=\left(\begin{array}{l}
u_{1}(t) \\
u_{m}(t)
\end{array}\right) E=\left(\begin{array}{l}
f_{1}(t) \\
f_{m}(t)
\end{array}\right)
$$

The hypothesis that the benchmark model is the best performing model can be defined in several ways. Derived from the previous equations we can state that we want to test the hypothesis $\mathrm{H}_{0}: \mathrm{u}_{\mathrm{k}} \leq 0$ for $\mathrm{k}=1, \ldots, \mathrm{m}$. An equivalent formulation for the vector is the following:

$$
\mathrm{H}_{0}=\mathrm{u} \leq 0
$$

Next, the stationary bootstrap method of Politis and Romano [30] is used to generate pseudo time series from $f_{k}$. The number of bootstrap replications is set at 500, as in Sullivan, Timmermann and White [5] and Hsu, Hsu and Kuan [7]. Brock, Lakonishok and LeBaron [14] state that p-values are not sensitive for a bootstrap replication size larger than 500. To acknowledge the length of our dataset, the block length is set at $t^{\wedge}(1 / 3)$. This approach is supported by Politis and White [31].

White [4] continues by constructing the following test statistic from the original technical trading returns and the 500 bootstrapped time series.

$$
T_{n}^{R C}=\max _{1<k<m} n^{1 / 2} \bar{f}_{k} \quad T_{n}^{R C, B}=\max _{1<k<m} n^{1 / 2}\left(\bar{f}_{k}^{B}-\bar{f}_{k}\right),
$$

The variable $\bar{f}_{k}$ is calculated as following:

$$
\bar{f}_{k}=\frac{1}{n} \sum_{t=1}^{n} \bar{f}_{k}(t)
$$

By comparing $T_{n}^{R C}$ and $T_{n}^{R C, B}$, we derive White's Reality Check p-value for the null hypothesis. However, Hansen [20] finds that this p-value can be manipulated when poor and irrelevant models are included. Therefore, he introduces the Superior Predictive Ability test (SPA), which changes the procedure of the Reality Check on two levels. Firstly, Hansen uses a studentized test statistic, in order to avoid the comparison of models which have different units of standard deviation. Secondly, Hansen utilizes a sample dependent null distribution. When executing the RC-test, all the trading rules are used to test the $\mathrm{H}_{0}$-hypothesis, which means that poor performing and irrelevant trading rules may influence the data snooping adjusted p-value. As an answer on this, Hansen's lower and consistent SPA p-values are introduced. Firstly, one has to determine which models perform worse than the benchmark. The lower bound p-value excludes all models that have higher losses than that benchmark. The consistent $\mathrm{p}$ value is the true $p$-value of the SPA test. This procedure excludes all models that perform worse than the threshold value $-2 \sqrt{\log \log n}$. This truncation point assures that irrelevant models are excluded from the SPA test. The test statistic is constructed as following: 


$$
\begin{aligned}
T_{n}^{S P A} \equiv \max _{k=1, \ldots, m} \frac{n^{1 / 2} \bar{f}_{k}}{\hat{\sigma}_{k}} \quad T_{n}^{S P A, B} \\
\quad \equiv \max _{k=1, \ldots, m} \frac{n^{1 / 2}\left(\bar{f}_{k}^{B}-\hat{u}_{k}^{c}\right)}{\hat{\sigma}_{k}}
\end{aligned}
$$

With $\hat{\sigma}_{k}^{2}=\widehat{\operatorname{var}}\left(n^{1 / 2} \bar{f}_{k}\right)$ as an estimator for variance in return, and $\hat{u}_{k}^{c}=\bar{f}_{k} 1_{n^{1 / 2} \bar{f}_{k} / \hat{\sigma}_{k} \leq-2 \sqrt{\log \log n}}$ as the threshold value that is used to remove the poor and irrelevant models. By comparing $T_{n}^{S P A}$ and $T_{n}^{S P A, B}$, we derive the consistent SPA pvalue for the null hypothesis.

In this survey, we will use three data snooping adjusted pvalues. The upper bound of our test is the conservative Reality Check p-value. The lower bound is the SPA lower p-value, while for the true $p$-value, we use the SPA consistent $p$-value.

\section{V.RESULTS}

In Table II and III we discuss the performance statistics of the trading models, before and after transaction costs. By interpreting the nominal p-values, before transaction costs, we can state that before accounting for data snooping, the performance of technical trading rules is strongly significant in all stock markets, except for Brazil and Latvia. These results are not surprising, as they correspond with literature on technical analysis in emerging markets, such as surveys of Gunasekarage and Power [16] and Chen, Huang and Lai [13]. After an adjustment of transaction costs is made, we still conclude that technical analysis is useful in the majority of the investigated stock markets. This positive evidence disappears when testing the performance of the best rule relative to the entire set of models. When looking at the difference between the consistent SPA p-value and nominal p-value, we find that data snooping has a huge influence on the performance of the best trading rule. For example in the case of Venezuela (table III), we find a significant nominal p-value of 0.000 . Nonetheless, the consistent $\mathrm{p}$-value that is produced by the Superior Predictive Ability Test equals 0.8180. After correcting for data snooping and transaction costs, significant excess returns are only found in the stock markets of Botswana, Jamaica, Kenya and Oman. The results are especially strong for Kenya, which yields a consistent SPA pvalue of 0.000 .

When interpreting Table II and III, we also can state that in the absence of transaction costs, the Alexander Filter rule with a filter size of $0.5 \%$, the 2 day Bollinger Band, and the 3 day Relative Strength Index are the best performing models in the majority of investigated markets. These specific rules often appear among the 10 best performing trading rules in the other stock market indices. After considering transaction costs, these results do not persist. An explanation for these outcomes can be found in the number of trading signals the algorithms produce. Because of the fact that the aforementioned models trade on small filter sizes and short time windows, trading signals emerge frequently. This implies that holding periods are very short, and transaction costs high. Consequently, the best returns when accounting for these trading costs appear for trading systems which trade less frequently. Examples are long-run oriented Exponential Moving Average Crossover Rules and Alexander Filter Rules with large filter sizes. As presented in Table IV, the holding periods for these trading rules are longer. The results correspond with research of Chen, Huang and Lai [13].

The best rules for each country that are presented in Table IV and V reveal very interesting information. Firstly, we find that in the majority of markets, technical trading rules generate more losing trades than winning trades. One would think that this is in support of the Efficient Market Hypothesis. Nevertheless, these models are still able to produce positive returns over the entire sample period. This is due to the fact that the profits that are achieved by the winning trades exceed the losses that are generated by the losing trades. The market in the period of research was very bullish, which might explain these exceeding long profits.

This study also uncovers remarkable differences in profitability between short trades and long trades. In the full sample period, long trades tend to be more successful than short trades, which support earlier research of Sullivan, Timmermann and White [5]. This result is observed on the level of average return per trade. In a reasonable number of markets, the differences are huge. For example for Mexico, we find that the average return per long trade is equal to $3,47 \%$, while the average return per short trade is only $0.20 \%$. This result is caused by the fact that the hit rate of long trades is significantly higher than the hit rate of short trades. Further long trades seem to have a longer holding period than short trades. These outcomes are very strong, since they occur all of investigated markets except for Hungary, Ecuador and Lebanon. In table VIII and IX, the same statistics per best trading rule are presented for the crisis period. The results contrast sharply with the statistics from the entire sample. During the crisis, short trades tend to be much more successful than long trades on the level of average return per trade. Further, the holding period of short positions is longer than for long positions. This result is not surprising, since the majority of markets are in a downward trend during the crisis.

In table VII and VI, we present the same statistics for the subsample of the recent economic crisis. We find that very different types of trading systems are identified as being the best performing model. Further, there is very little connection between the best performer during the full sample period, and the best rule during the crisis subsample. This means that the performance of the algorithms seems to be very datadependent. Remarkably, we find that during the crisis the Moving Average Convergence Divergence system is among the best performing algorithms, while this particular model underperforms most trading rules during the full sample period.

Table VI provides an overview of the same performance statistics for the subsample. We find during the crisis period significant data snooping adjusted p-values in Nigeria, Kenya, Zambia, Botswana, Lithuania, Bulgaria and Estonia. These results are obtained after a consideration of data snooping and 
transaction costs. It is interesting to notice that these excess returns are found either in African or in East European markets. Further, we find that for 22 markets the mean daily return is higher during the sub period compared to entire sample period. The abovementioned results may mean that market inefficiencies are more likely to appear during crisis periods. Nevertheless, we conclude that even during these periods, it is very difficult to make profits on a consistently basis by using technical analysis.

Important to notice is that in some markets - Latvia and Ecuador -, data snooping adjusted p-values after accounting for transaction costs are more significant than the p-values before making this adjustment. The reason for these outcomes is due to the fact that in both situations, the same trading rule is detected as best performer. This specific algorithm produces very few trading signals, which implies that transaction costs remain low. Consequently, the other models will suffer more from the adjustment for transaction costs than the best rule, and the performance of this algorithm relative to the entire set of rules will be more significant.

As expected, our results indicate differences between the RC-test and SPA-test. These outcomes are in support of research of Hansen [6] and Hansen and Lunde [20], who state that the inclusion of one or more poor performing models can have a large influence on the Reality Check p-value. This can have a large impact on the conclusions of a survey. Consider the performance statistics of Botswana. When interpreting the $\mathrm{RC}$ p-value, which is equal to 0.0560 , one would conclude that the best trading rule is not able to outperform the buy-andhold benchmark. However, when we inspect the consistent SPA p-value, which signals 0.0360 , one would state that the $\mathrm{H}_{0}$-hypothesis that the benchmark is the best model should be rejected. These results indicate that the Reality Check unfairly punishes the best performing trading rule when a large number of poor performing models are present.

\section{CONCLUSION}

Over the years, there has been a large academic interest in the usefulness of technical trading rules. A fundamental problem is to take the whole universe of trading algorithms into consideration when testing their performance. Our survey addresses this issue by composing a very large number of trading rules, and by using White's [4] Reality Check and Hansen's [6] Test for Superior Predictive Ability. By using these methods, we are able to provide strong evidence that data snooping bias has an immense effect on technical trading rule performance evaluation. We conclude that when adjustments for transaction costs and data snooping bias are made, technical trading rules are not able to outperform a passive buy-and-hold strategy on a consistently basis, except for 4 countries. Further, we provide evidence that during the recent economic crisis, market inefficiencies were present in 7 investigated markets. We also indicate that the algorithms make more losing trades than winning trades. Further, we find significant differences between short trades and long trades. When considering the full sample period, the results are in favor of long trades, while during the crisis, results reveal the opposite. This may mean that the investigated trading rules still have room for improvement and refinement.

Important to notice is that this only examines historical performance of technical analysis. We do not present evidence that investors are capable of detecting the best technical trading rule ex ante. Further, it can be interesting to extend this study by testing the profitability of combination systems, which generate trading signals when two or more trading systems are in accordance with each other. Notice, however, that even if these trading rules achieve higher returns, this will not automatically lead to more significant results. The effect of testing technical trading profitability in a larger set of trading rules may dominate the improved performance of the best trading rule, leading to higher data snooping adjusted $\mathrm{p}$ values.

\section{REFERENCES}

[1] Lo, A. (2004). The adaptive markets hypothesis: Market efficiency from an evolutionary perspective, Journal of Portfolio Management, 30, 1529.

[2] McKenzie, M.D. (2007). Technical Trading Rules in Emerging Markets and the 1997 Asian Currency Crises, Emerging Markets Finance and Trade, 43, 46-73.

[3] Marshall, B., Cahan, R.C., Cahan, J.M. (2010) Technical Analysis Around The World, working paper, Massey University New Zealand.

[4] White, H. (2000). A Reality Check for data snooping, Econometrica, 68, 1097-1126.

[5] Sullivan, R., Timmermann, A., White, H. (1999). Data snooping, technical trading rule performance, and the bootstrap, Journal of Finance 54, 1647-1691.

[6] Hansen, P.R. (2005). A test for Superior Predictive Ability, Journal of Business \& Economic Statistics, 23, 365-380.

[7] Hsu, P.H., Hsu Y.-C., Kuan, C.H. (2010). Testing the Predictive Ability of Technical Analysis Using a New Stepwise Test without Data Snooping Bias. Journal of Empirical Finance, 17:3, 471-484.

[8] Fama, E. (1970). Efficient capital markets: a review of theory and empirical work, Journal of Finance, 25, 25-52.

[9] Jensen, M.C. (1968). The performance of mutual funds in the period 1945-1964, Journal of Finance, 23, 389-416.

[10] Malkiel, B.G. (1973). A Random Walk Down Wall Street, New York, Norton, 1-428.

[11] Malkiel, B.G. (2003). The efficient market hypothesis and its critics. Journal of Economic Perspectives, 17, 59-82.

[12] Li, W., Wang, S.W. (2007). Ownership Restriction, Information Diffusion Speed, and the Performance of Technical Trading Rules in Chinese Domestic and Foreign Shares Markets, Review of Pacific Basin Financial Markets and Policies, 10:4, 585-617.

[13] Chen, C-W., Huang, C-S., Lai, H-W. (2009). The impact of data snooping on the testing of technical analysis: An empirical study of Asian stock markets. Journal of Asian Economics, 20, 580-591.

[14] Lukac, L.P., Brorsen, B.W., Irwin, S.H. (1998). A Test of Futures Market Disequilibrium using Twelve Different Technical Trading Systems, Applied Economics, 20, 623-639.

[15] Brock, W., Lakonishok, J., LeBaron, B. (1992). Simple technical trading rules and the stochastic properties of stock returns, Journal of Finance, 47, 1731-1764.

[16] Gunasekarage, A., Power, D.M. (2001). The Profitability of Moving Average Trading Rules in South Asian Stock Markets, Emerging Markets Review, 2, 17-33.

[17] Fifield, S., Power, D., Sinclair, D. (2005). An analysis of trading strategies in eleven European stock markets, European Journal of Finance, 11, 531-548.

[18] Bessembinder, H., Chan, K. (1998). Market Efficiency and the Returns to Technical Analysis. Financial Management, 27, 5-17.

[19] Timmermann, A., Granger, C.W.J. (2004). Efficient market hypothesis and forecasting, International Journal of Forecasting, 20, 15-27 
[20] Hansen, P.R., Lunde A. (2005). A forecast comparison of volatility models: Does anything beat a $\operatorname{GARCH}(1,1)$ ? Journal of Applied Econometrics, 20, 873-889.

[21] Marshall, B., Qian, S., Young, M. (2009). Is technical analysis profitable on US stocks with certain size, liquidity or industry characteristics? Applied Financial Economics, 19, 1213-1221.

[22] Lo, A., McKinlay, C. (1988). Stock Do Not Follow Random Walks, Review of Financial Studies (Spring), 41-66.

[23] Fama, E., French, K. (1988). Permanent and Temporary Components of Stock Prices, Journal of Political Economy, 96:2, 246-274.

[24] Papathanasiou, S., Samitas A. (2010). Profits from Technical Trading Rules: The Case of Cyprus Stock Exchange, Journal of Money, Investment and Banking, 13, 35-43.

[25] Hsu, P.H., Kuan, C.H. (2005). Re-examining the profitability of technical analysis with data snooping checks. Journal of Financial Econometrics, 3, 606-628.

[26] Park, C.H., Irwin, S.H. (2010). A Reality Check on Technical Trading Rule Profits in the U.S. Futures Market. Journal of Futures Markets,30:7, 633-659.

[27] Munck, N.H. (2005). When Transactions Went High-Tech: A CrossSectional Study of Equity Trading Costs in the Light of More Sophisticated Trading Systems, SSRN Working Paper.

[28] Diebold, F.X., Mariano, R.S. (1995). Comparing Predictive Accuracy, Journal of Business and Economic Statistics, 13, 253-263.

[29] West, K.D. (1996). Asymptotic Inference About Predictive Ability, Econometrica, 64, 1067-1084.

[30] Politis, D.N., Romano, J.P. (1994). The Stationary Bootstrap. Journal of the American Statistical Association, 89, 1303-1313.

[31] Politis, D.N., White, H. (2004). Automatic Block-Length Selection for the Dependent Bootstrap, Econometric Reviews, 23:1, 53-70. 
TABLE I

SUMMARY STATISTICS

THIS TABLE REPORTS THE SUMMARY STATISTICS FOR 34 EMERGING STOCK MARKET INDICES. FOR EACH COUNTRY, THE LONGEST POSSIBLE SAMPLE PERIOD IS USED. TRANSACTION COSTS ALTER FOR EACH SPECIFIC INDEX

\begin{tabular}{|c|c|c|c|c|c|}
\hline \multirow[t]{2}{*}{ Country } & \multicolumn{2}{|l|}{ Sample Period } & \multirow{2}{*}{$\begin{array}{c}\text { Number of } \\
\text { observations }\end{array}$} & \multirow{2}{*}{$\begin{array}{c}\text { Transaction } \\
\text { costs }\end{array}$} & \multirow{2}{*}{$\begin{array}{c}\text { Average return } \\
\text { per year }\end{array}$} \\
\hline & start & end & & & \\
\hline Argentina & 20 December 1993 & 28 February 2011 & 4486 & $0,42 \%$ & $16,49 \%$ \\
\hline Bahrain & 22 May 2003 & 28 February 2011 & 2028 & $0,35 \%$ & $4,29 \%$ \\
\hline Botswana & 17 September 2001 & 28 February 2011 & 2466 & $0,35 \%$ & $12,00 \%$ \\
\hline Brazil & 10 May 1990 & 28 February 2011 & 5428 & $0,40 \%$ & $94,85 \%$ \\
\hline Bulgaria & 9 March 2001 & 28 February 2011 & 2602 & $0,35 \%$ & $20,00 \%$ \\
\hline Chile & 22 May 1987 & 28 February 2011 & 6202 & $0,35 \%$ & $18,58 \%$ \\
\hline Colombia & 20 November 2001 & 28 February 2011 & 2420 & $0,55 \%$ & $31,61 \%$ \\
\hline Czech Republic & 24 August 1994 & 28 February 2011 & 4309 & $0,37 \%$ & $5,63 \%$ \\
\hline Ecuador & 20 December 1993 & 28 February 2011 & 4486 & $0,35 \%$ & $-1,40 \%$ \\
\hline Egypt & 22 May 1995 & 28 February 2011 & 4116 & $0,56 \%$ & $14,02 \%$ \\
\hline Estonia & 22 May 2000 & 28 February 2011 & 2811 & $0,40 \%$ & $16,16 \%$ \\
\hline Hungary & 22 May 1991 & 28 February 2011 & 5159 & $0,37 \%$ & $18,13 \%$ \\
\hline India & 22 May 1987 & 28 February 2011 & 6202 & $0,59 \%$ & $18,34 \%$ \\
\hline Indonesia & 22 August 1983 & 28 February 2011 & 7182 & $0,52 \%$ & $15,63 \%$ \\
\hline Jamaica & 29 October 1987 & 28 February 2011 & 6088 & $0,35 \%$ & $17,75 \%$ \\
\hline Jordan & 10 April 1989 & 28 February 2011 & 5711 & $0,35 \%$ & $9,37 \%$ \\
\hline Kenya & 31 May 1990 & 28 February 2011 & 5413 & $0,35 \%$ & $9,38 \%$ \\
\hline Kuwait & 17 May 1995 & 28 February 2011 & 4119 & $0,35 \%$ & $31,92 \%$ \\
\hline Latvia & 22 May 2000 & 28 February 2011 & 2811 & $0,40 \%$ & $14,78 \%$ \\
\hline Lebanon & 10 Juin 1996 & 28 February 2011 & 3841 & $0,35 \%$ & $5,28 \%$ \\
\hline Lithuania & 22 May 2000 & 28 February 2011 & 2811 & $0,40 \%$ & $14,24 \%$ \\
\hline Malaysia & 21 May 1980 & 28 February 2011 & 8029 & $0,41 \%$ & $8,01 \%$ \\
\hline Mexico & 23 May 1988 & 28 February 2011 & 5941 & $0,40 \%$ & $25,56 \%$ \\
\hline Morocco & 22 May 2002 & 28 February 2011 & 2289 & $0,35 \%$ & $15,35 \%$ \\
\hline Nigeria & 2 Juin 2000 & 28 February 2011 & 2802 & $0,35 \%$ & $15,56 \%$ \\
\hline Oman & 11 March 1997 & 28 February 2011 & 3645 & $0,35 \%$ & $7,95 \%$ \\
\hline Pakistan & 19 May 1989 & 28 February 2011 & 5682 & $0,35 \%$ & $15,66 \%$ \\
\hline Poland & 19 January 1996 & 28 February 2011 & 3146 & $0,42 \%$ & $11,36 \%$ \\
\hline Romania & 6 February 1998 & 28 February 2011 & 3407 & $0,35 \%$ & $19,65 \%$ \\
\hline Russia & 8 February 1999 & 28 February 2011 & 3941 & $0,32 \%$ & $29,94 \%$ \\
\hline South Africa & 17 November 1995 & 28 February 2011 & 3987 & $0,38 \%$ & $13,26 \%$ \\
\hline Turkey & 23 May 1988 & 28 February 2011 & 5941 & $0,38 \%$ & $48,40 \%$ \\
\hline Venezuela & 19 August 1993 & 28 February 2011 & 4573 & $0,83 \%$ & $27,28 \%$ \\
\hline Zambia & 22 May 1997 & 28 February 2011 & 3593 & $0,35 \%$ & $25,59 \%$ \\
\hline
\end{tabular}




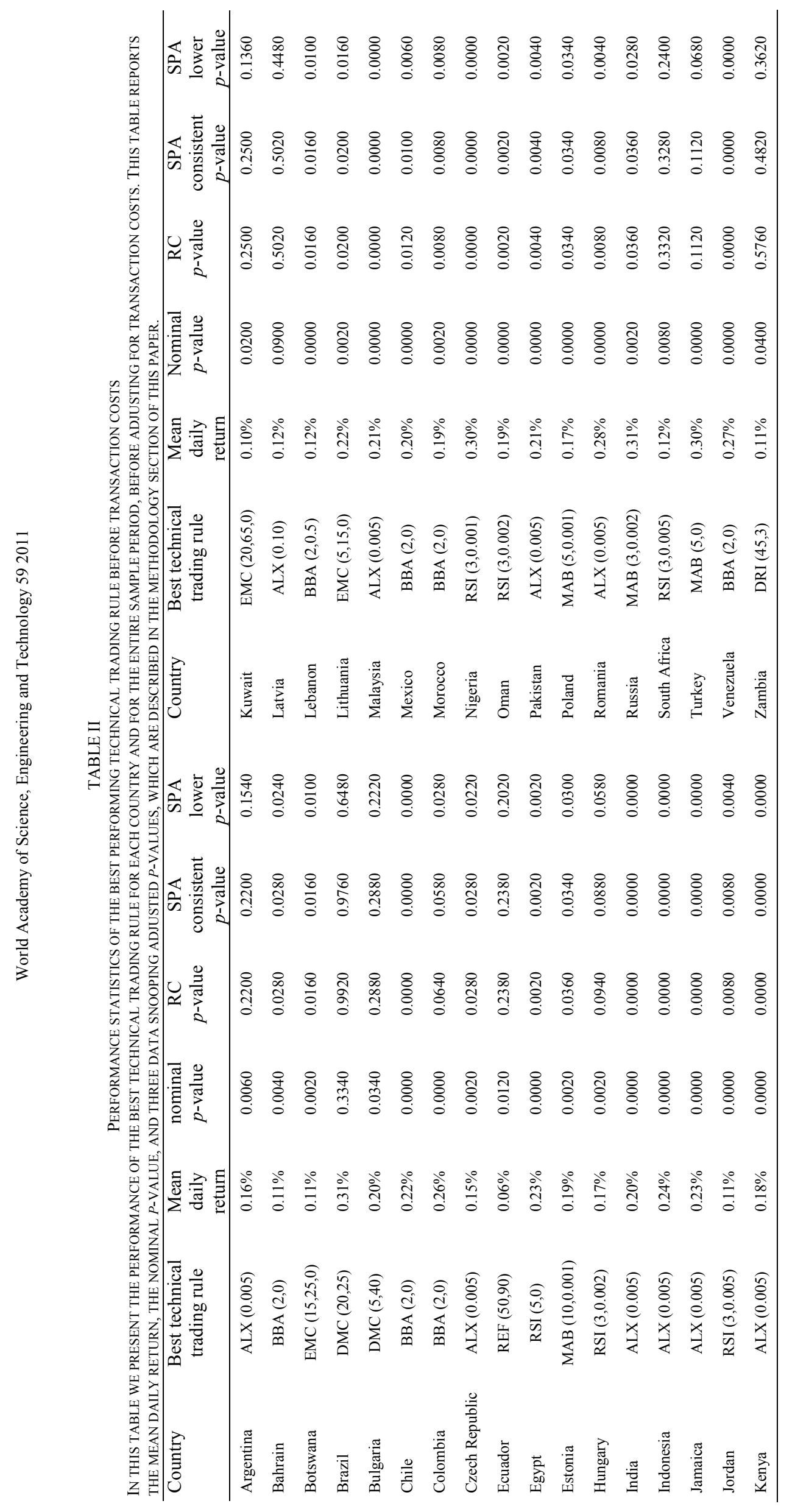




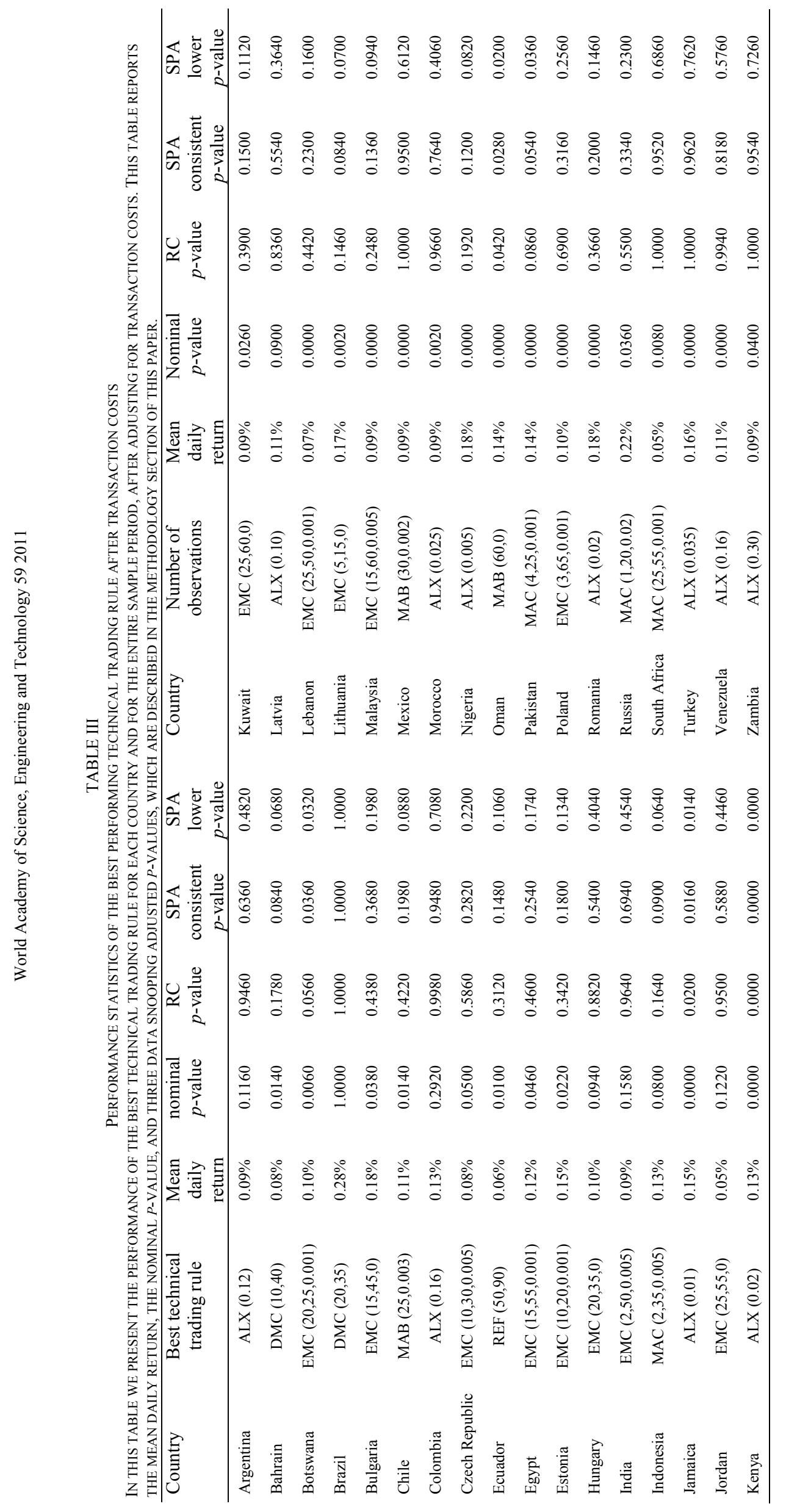




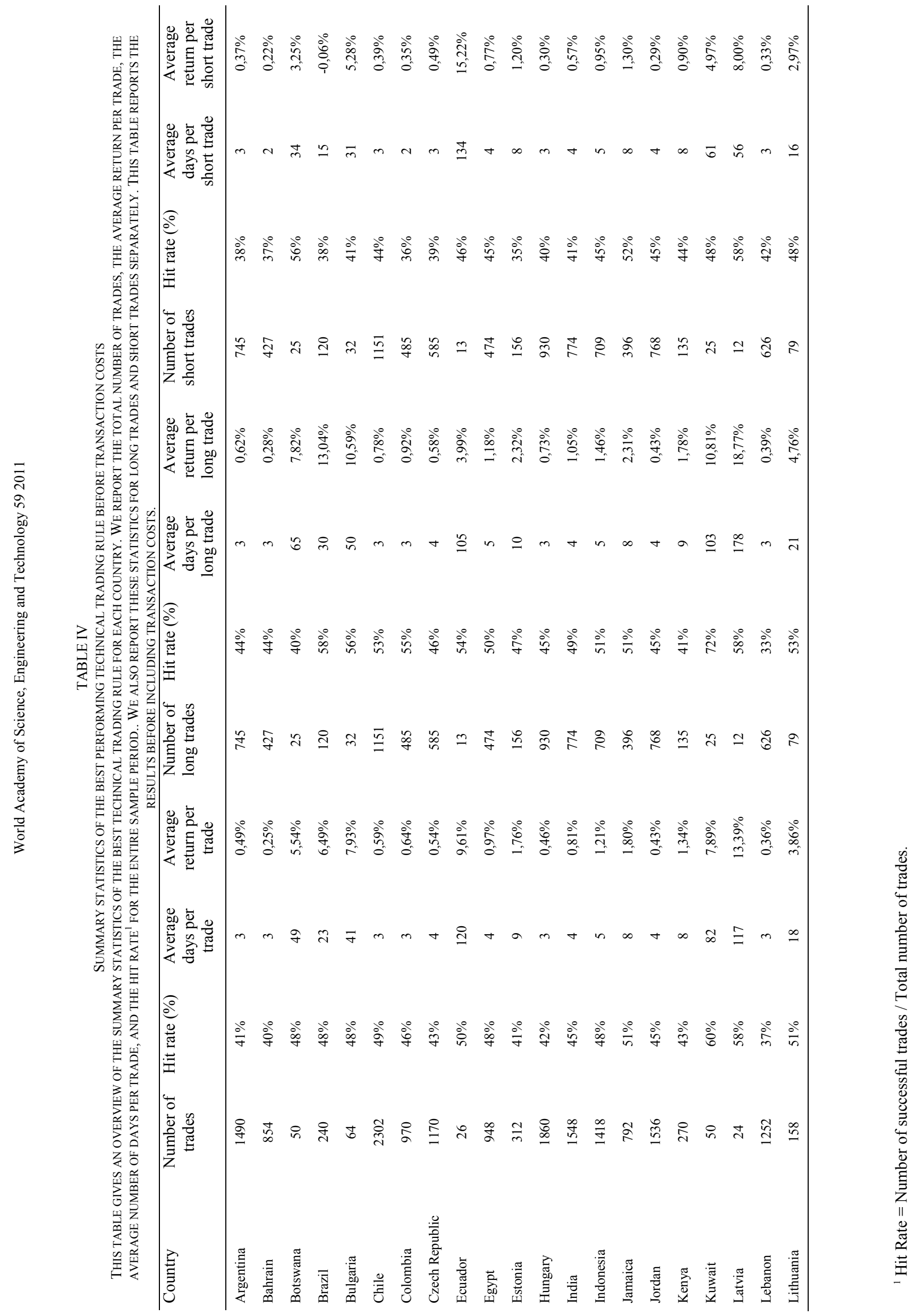




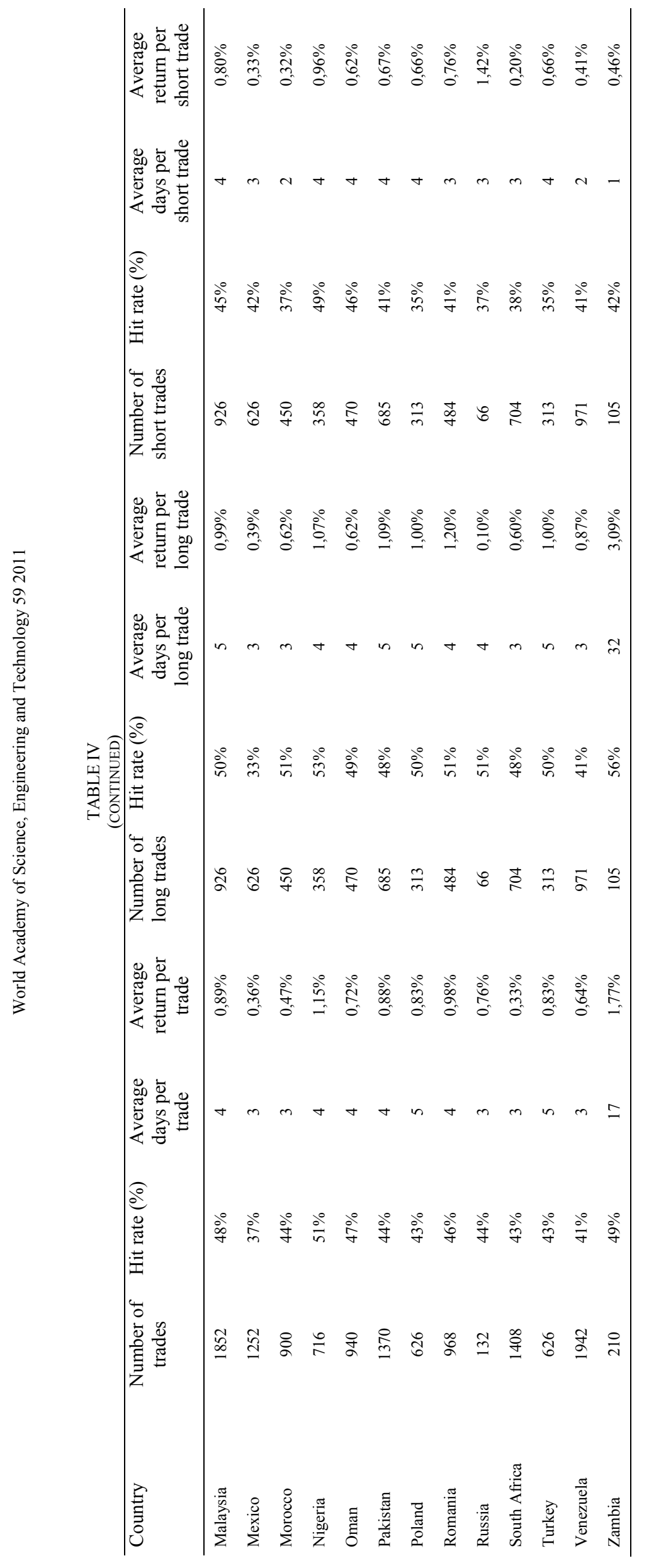




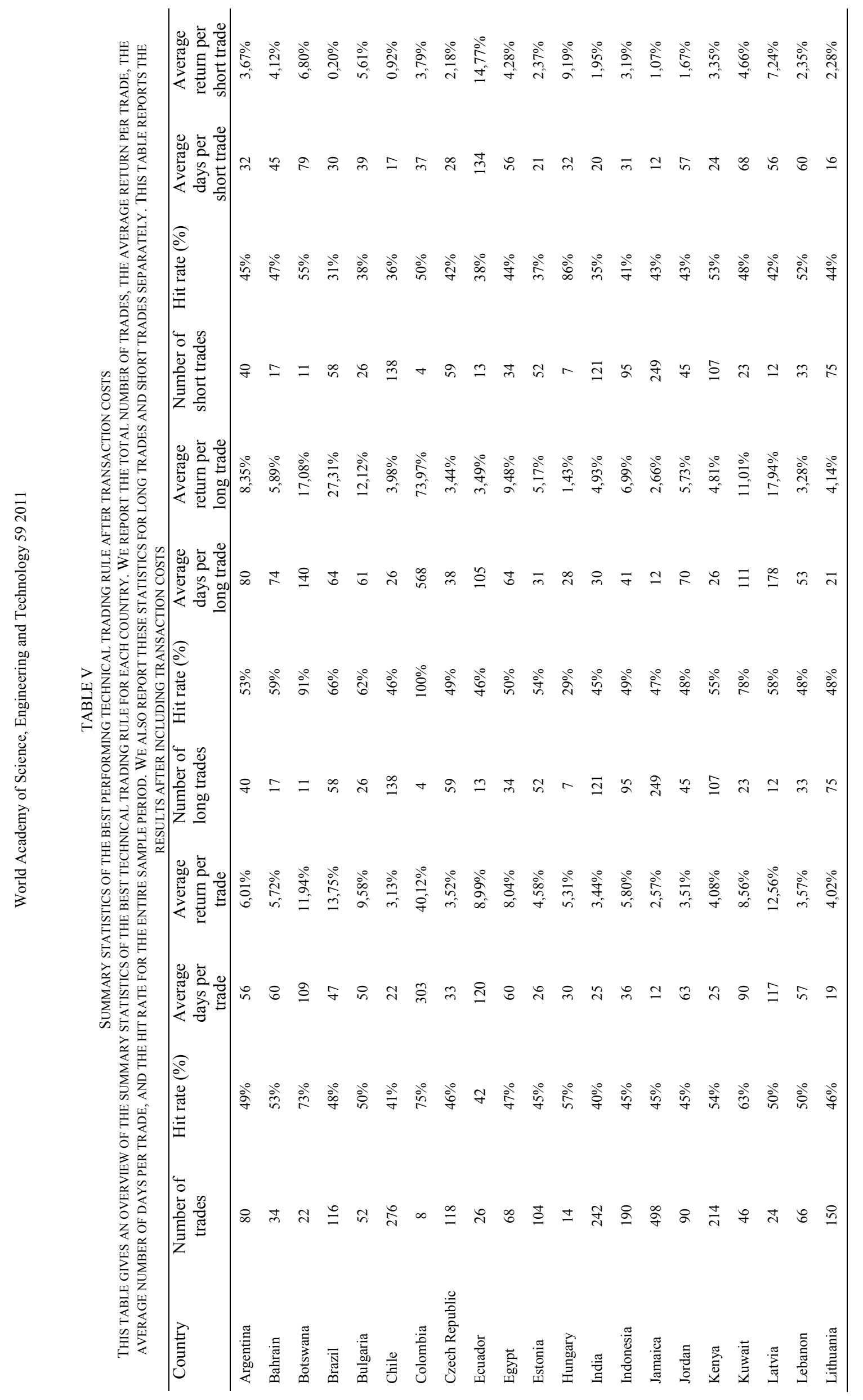




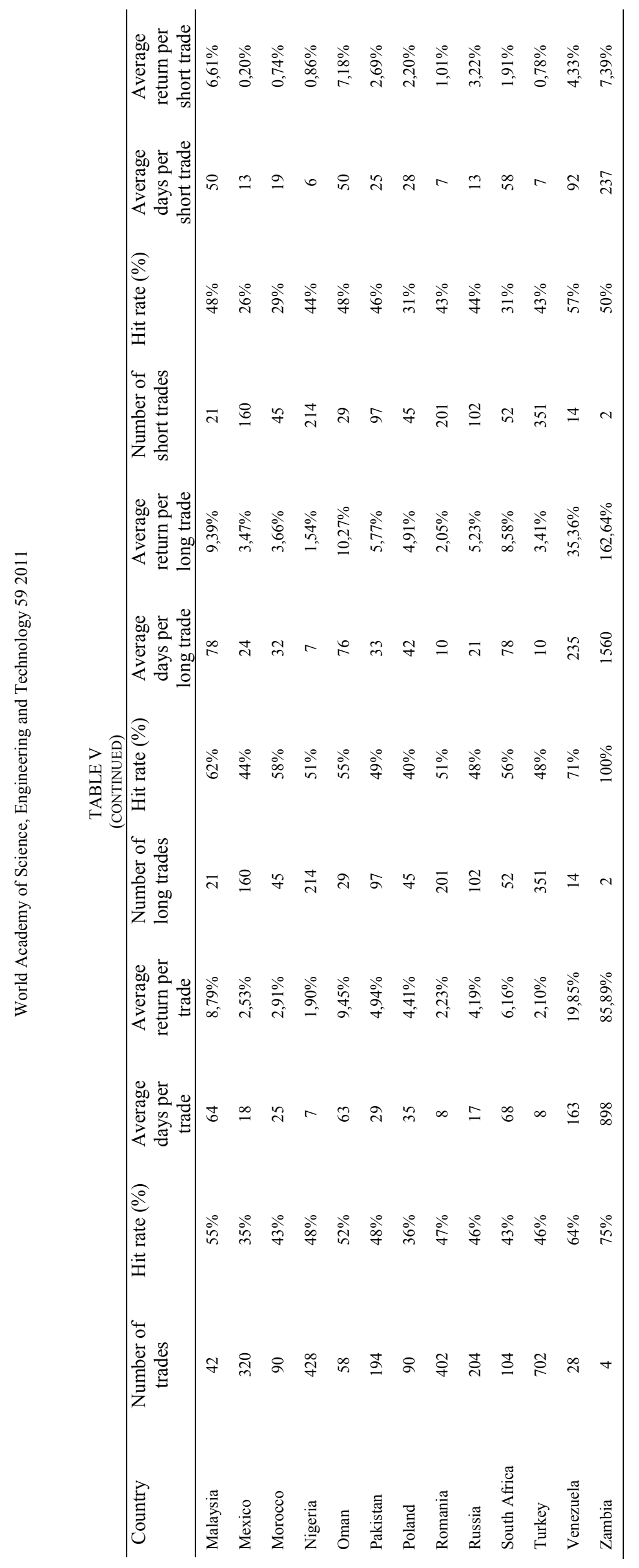




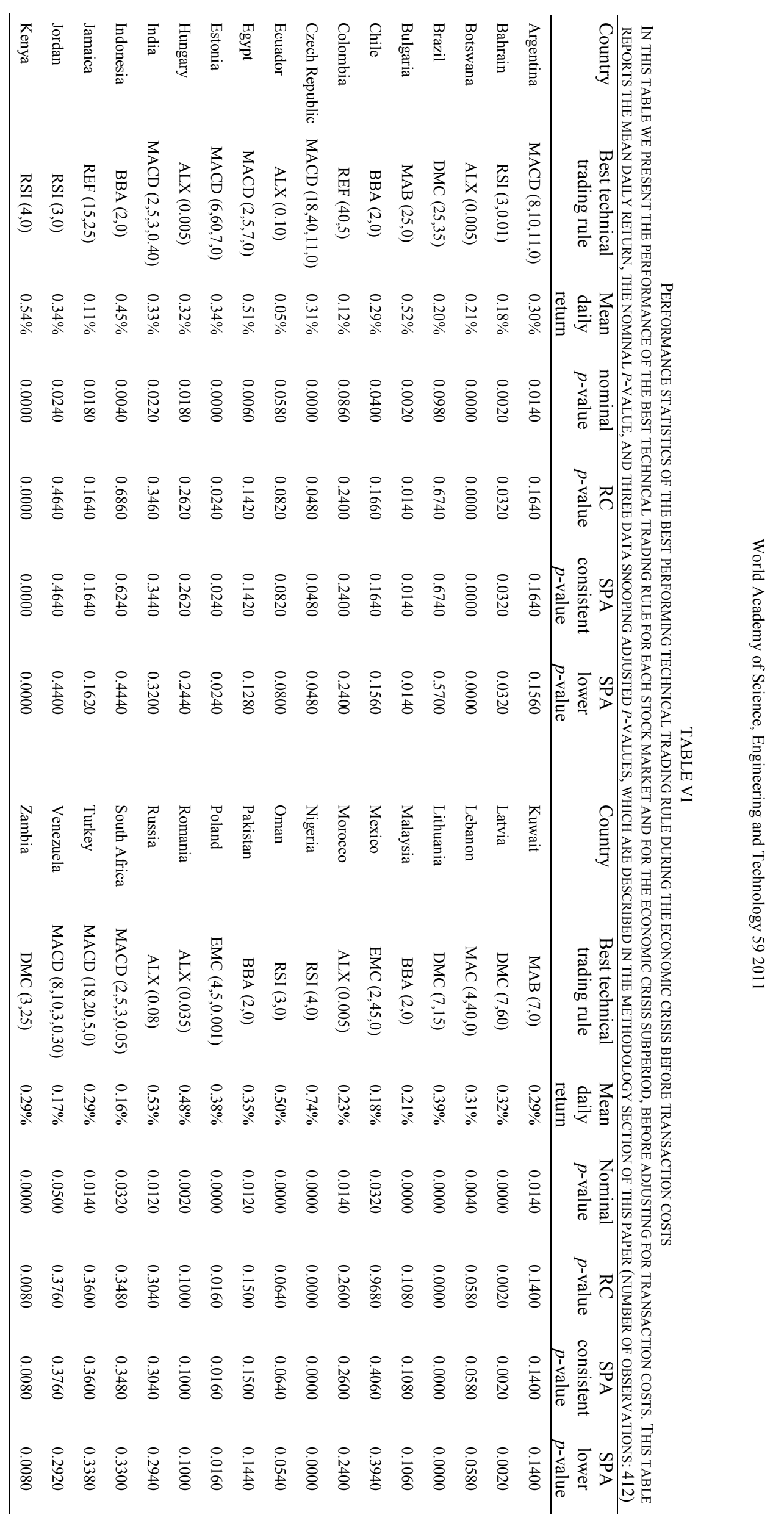




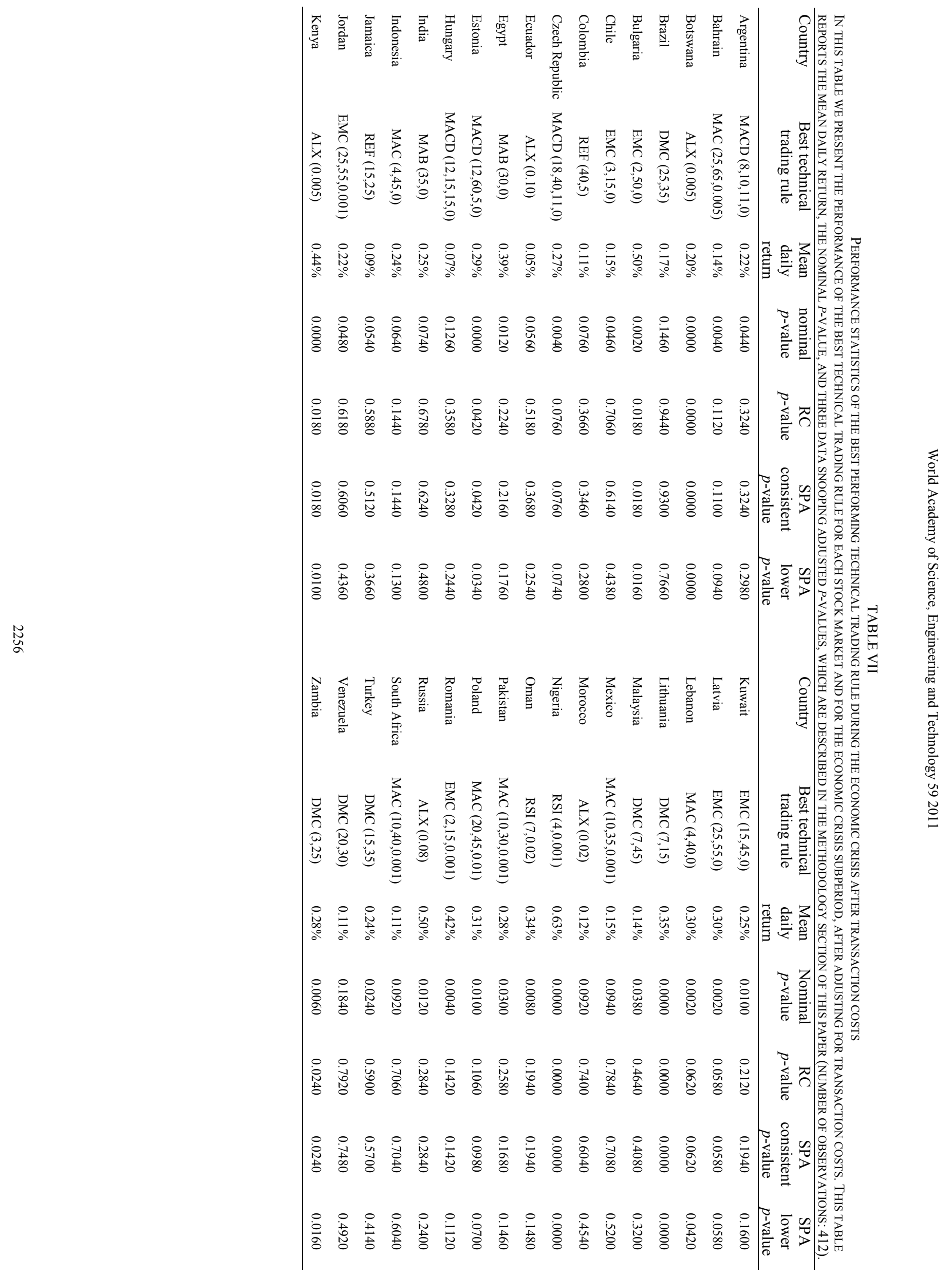




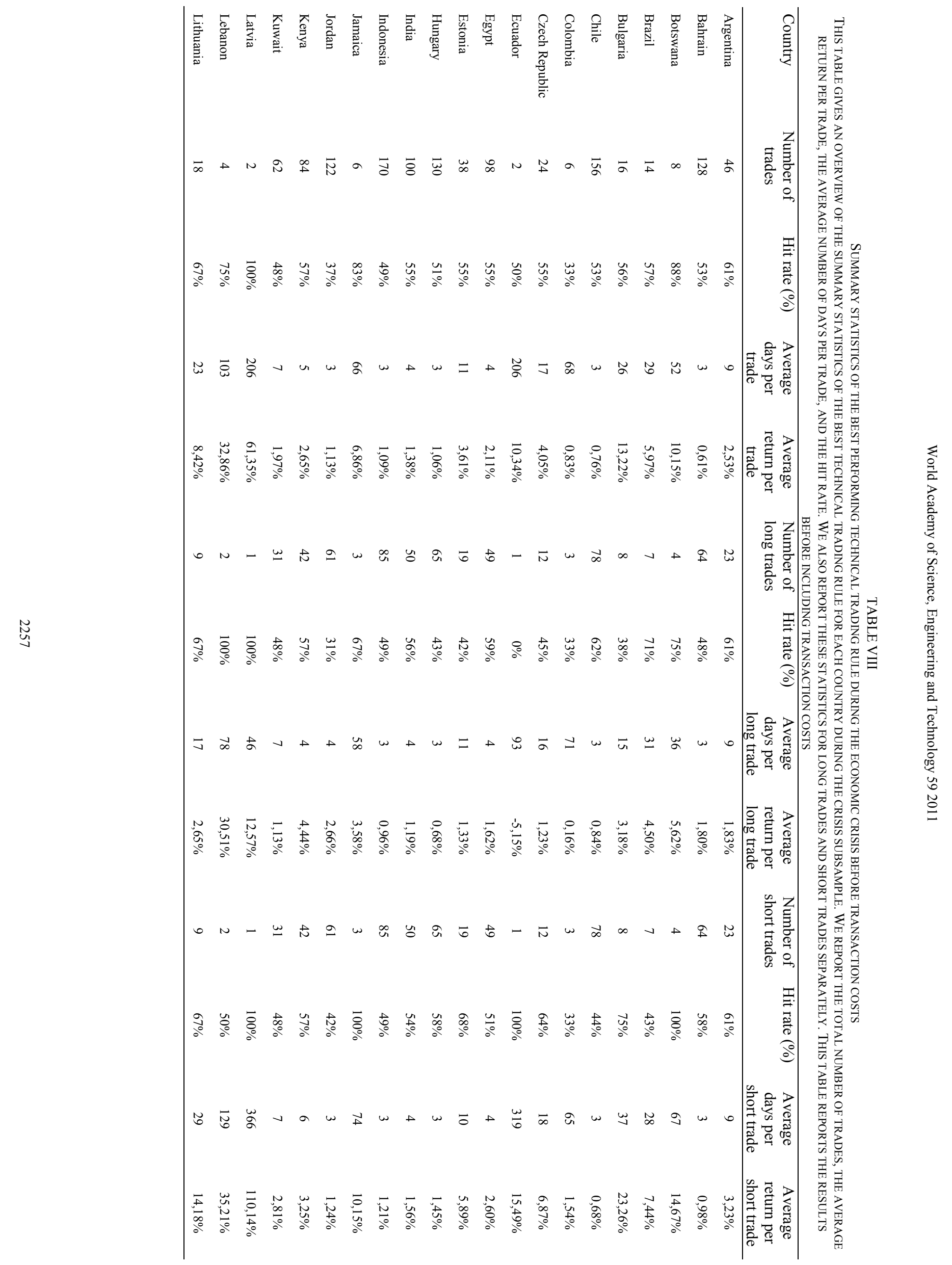




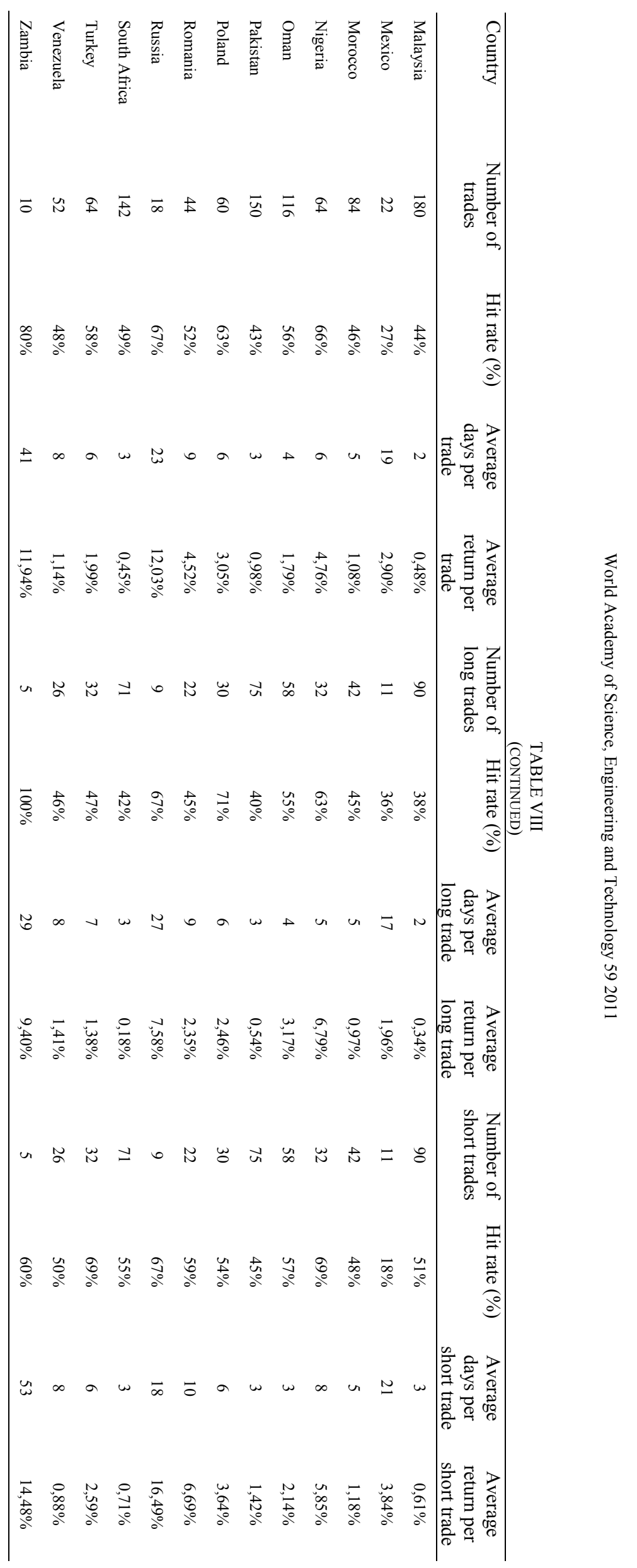




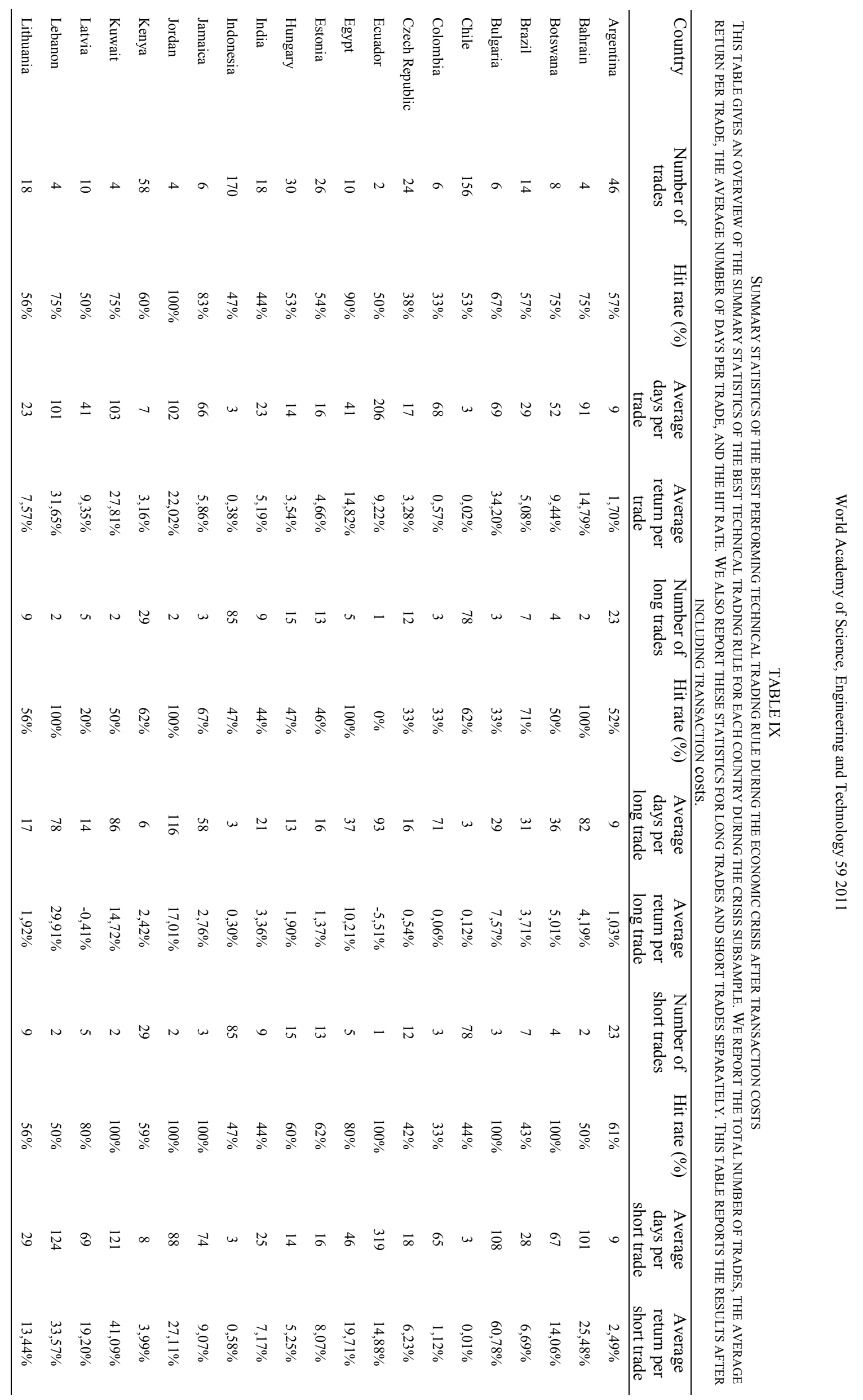




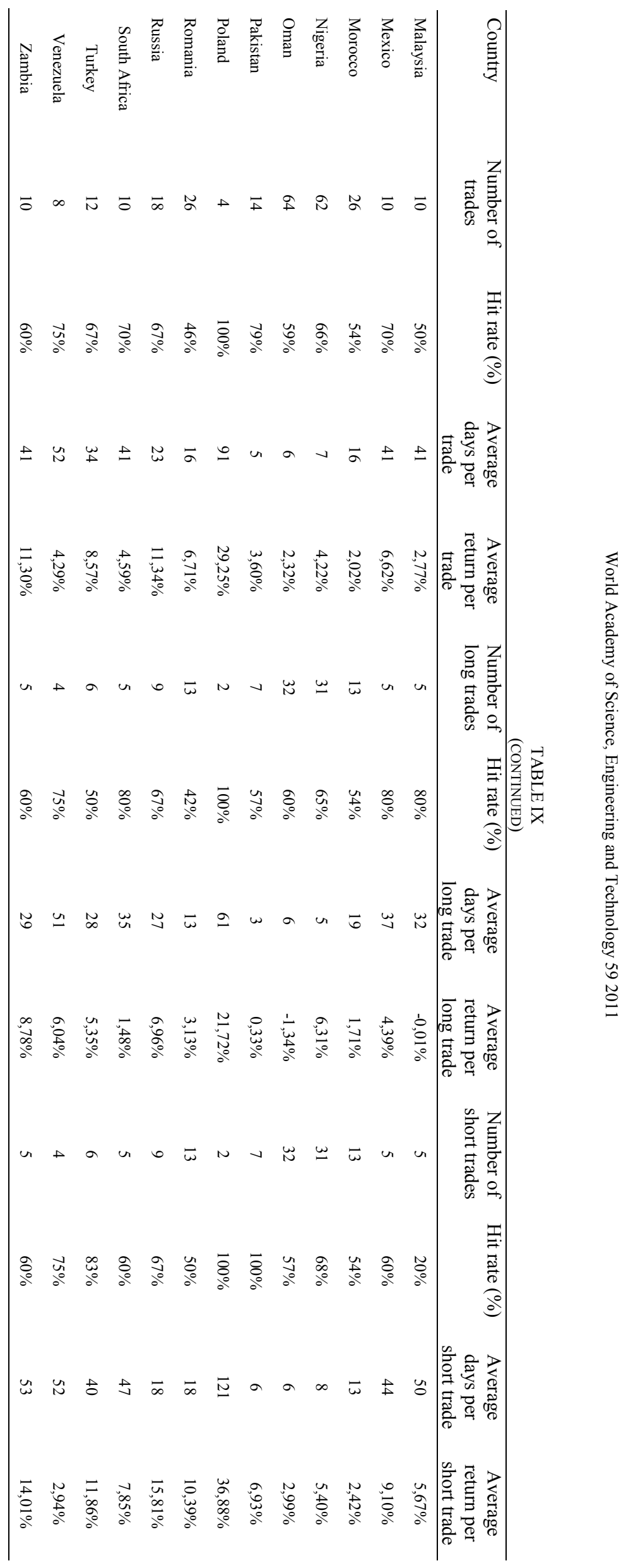




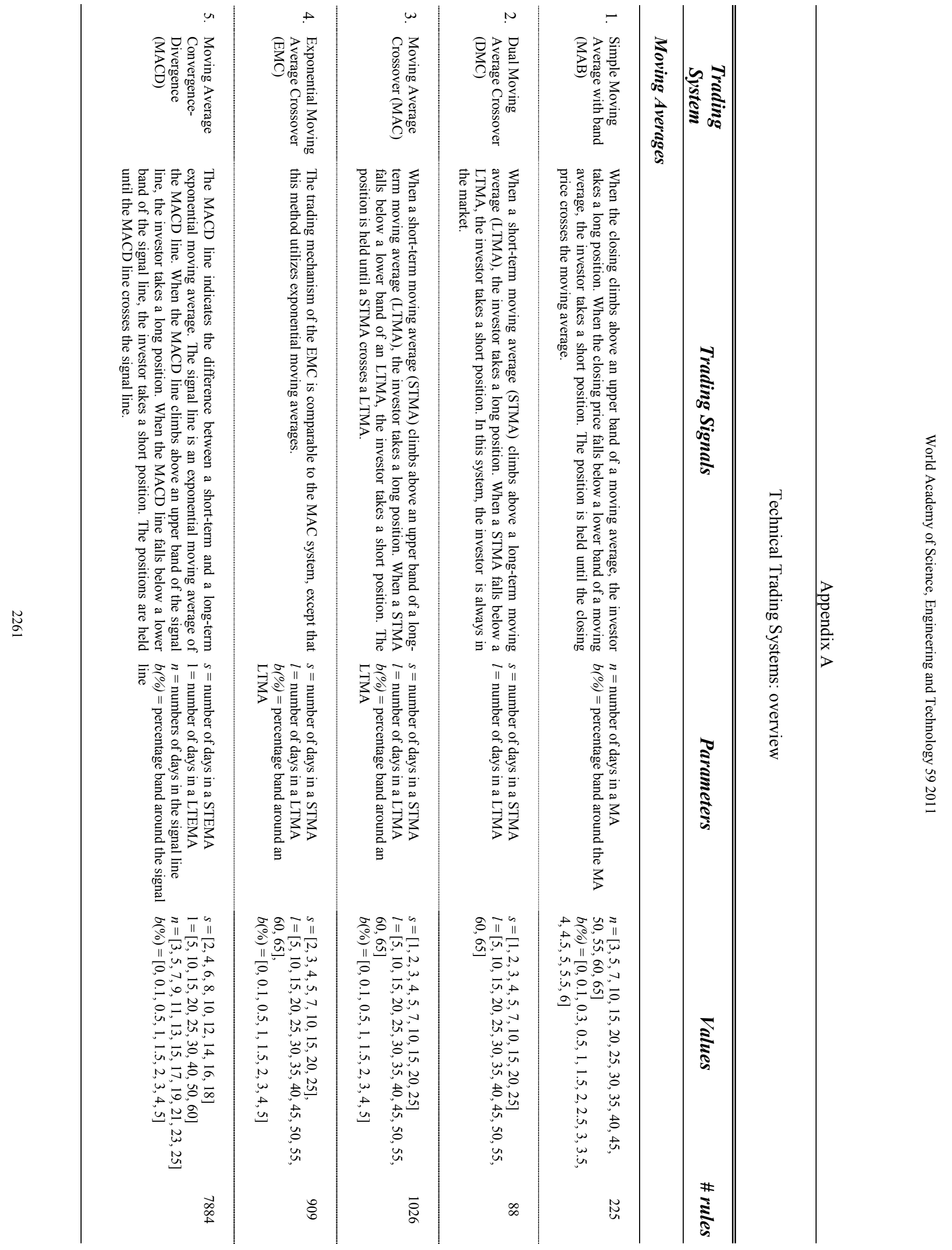




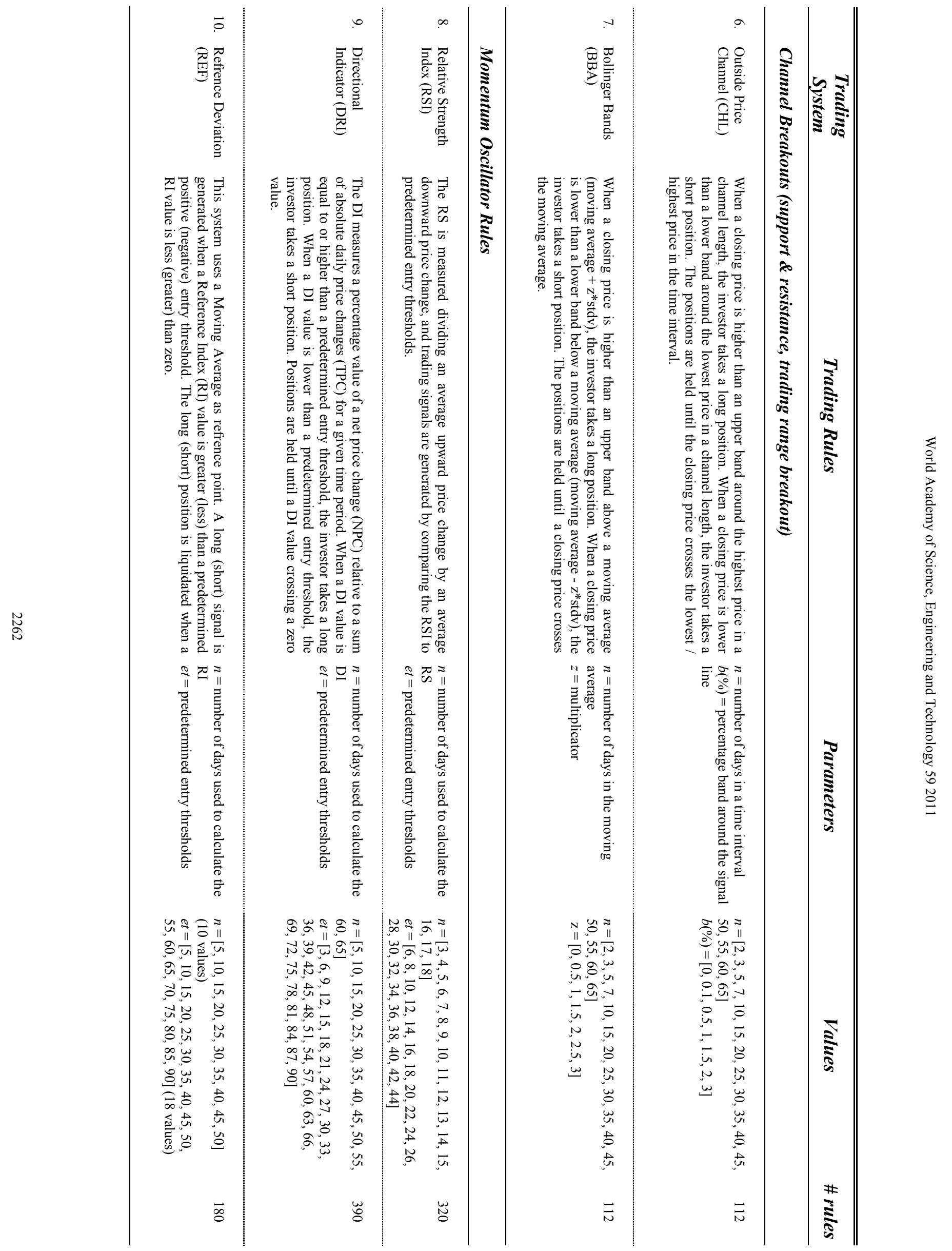




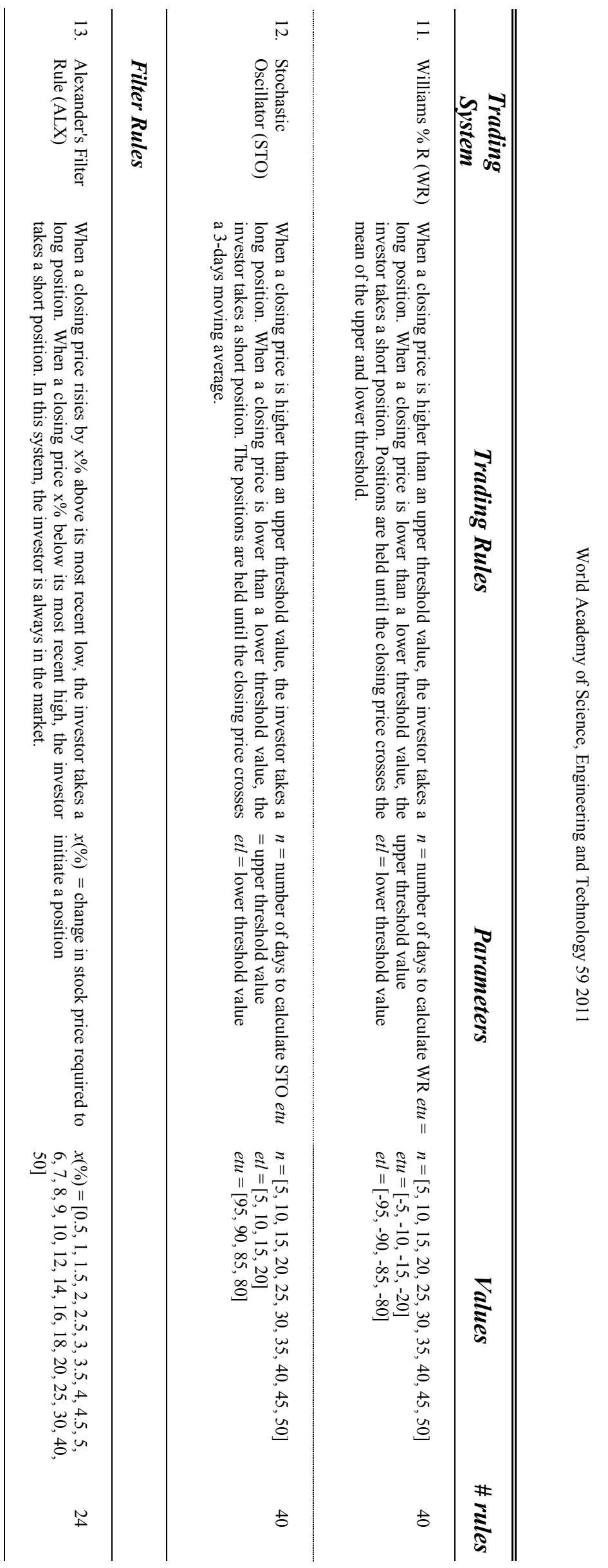


Stefaan Pauwels. Department of Financial Economics, Ghent Univeristy, Ghent University, Woodrow Wilsonplein 5D (phone: +32498676446; e-mail: stefaan.pauwels@ugent.be).

Koen Inghelbrecht, Department of Financial Economics, Ghent Univeristy, Ghent University, Woodrow Wilsonplein 5D (e-mail: koen.inghelbrecht@ugent.be).

Dries Heyman, Department of Financial Economics, Ghent Univeristy, Ghent University, Woodrow Wilsonplein 5D (e-mail: dries.heyman@ugent.be).

Pieter Marius, Financial Data Management, Dexia (email:npieter.marius@dexia.com) 